\title{
Introduction to: The 'Seal' of Sir Shackleton
}

\author{
Bruce A. Griffin ${ }^{1}$
}

Published online: 12 August 2020

(c) Springer-Verlag GmbH Germany, part of Springer Nature 2020

Ketosis is a metabolic state characterized by a raised level of ketone bodies in the blood, produced from the excessive breakdown of body fat, once carbohydrate stores are depleted. Ketosis can lead to the life-threatening condition of ketoacidosis in diabetes, whereas milder ketosis can also be induced, and tolerated, through starvation, and by a low carbohydrate-high fat diet. While the latter, 'ketogenic diets' have been popularised as a weight-losing strategy, there is emerging evidence to suggest that these diets may have clinical utility in the treatment of Alzheimer's disease [1]. In support of these potential benefits of a ketogenic diet, the following Letter by Cognat et al. presents anecdotal evidence from Sir Ernest Shackleton's final expedition to the Antarctic in 1914. 'The 'Seal' of Sir Shackleton' entertains the possibility that the different plights of two separate parties of men, led by Sir Shackleton and Captain Mackintosh, was attributed to the beneficial impact of a ketogenic diet on mental performance.

\section{Reference}

1. Lilamand M, Porte B, Cognat E et al (2020) Are ketogenic diets promising for Alzheimer's disease? A translational review. Alzheimers Res Ther 12:42

This Introduction refers to the following letter: https://doi. org/10.1007/s00394-020-02349-3.

A reply to the letter can be read here: https://doi.org/10.1007/ s00394-020-02350-w.

Bruce A. Griffin

b.griffin@surrey.ac.uk

1 Department of Nutritional Sciences, Faculty of Health and Medical Sciences, University of Surrey, Surrey, UK 